\title{
The role of the practice nurse in the management of chroni obstructive pulmonary disease (COPD
}

\author{
Rupert C M Jones, Sam Freegard, Mark Reeves, Karen Hanney, Frank Dobb
}

\author{
TBSTRAC \\ sim \\ To assess the range of activities performed by practice nurses $\mathrm{i}$ \\ COPD management and their training for these tasks
}

\section{Methods}

A postal questionnaire was sent to the nurse with prim desponsibility for respiratory care in 179 practices in Cornwall an Southwest Devon

\section{Results}

TThe response rate was $64 \%$. Spirometers were available in $64 \%$ o practices (range 0-6 per practice). Of these, spirometry wa performed by nurses alone in $72 \%$; in $44 \%$ spirometry wa performed less than once a week. Spirometry was used for diagnosi

in $91 \%$; monitoring in $87 \%$ and screening asymptomatic smokers i $45 \%$. Reversibility testing was performed by $61 \%$ of the practices Formal training in spirometry had been undertaken by $52 \%$ informal training in $41 \%$ and none in $7 \%$. They would like to se the development of one-stop COPD clinics, support from specialis qurses and pulmonary rehabilitation, preferably based in th community.

\section{Conclusio}

Nurses face many problems managing COPD in general practic including equipment, training and professional support

\section{Keyword}

Practice nurses, Primary Care, Questionnaire, Chronic Obstructiv Pulmonary Disease

\section{Introductio}

COPD is a common respiratory disease with hig morbidity and mortality ${ }^{1}$ the direct health servic nosts are enormous, estimated at over $£ 300$ million i 1996 with indirect costs estimated at $£ 630$ million ${ }^{2}$ She disease affects $20 \%$ of smokers with relentles progression ${ }^{3}$ damage to lung tissue is often sever swith considerable debility, before medical advice i dought. Accurate diagnosis at an early stage with goo management of patients can prevent or reduce th lung damage ${ }^{4}$

Rrimary Care is well placed to deal with COPD give she scale of the disease burden, however it appear that COPD has been neglected in the past. With th publication of guidelines from the British Thoraci Societ ${ }^{1}$ clearly outlining the optimum managemen of COPD, many practices are offering new services t their patients. What is not clear is how widely th fecommendations for diagnosis and management $\mathrm{o}$ COPD are implemented in practice

Diagnosis of COPD can only be made wit spirometry ${ }^{1}$ but many practices do not own spirometer ${ }^{6}$, th those that do, it is often under use and training inadequate. There may be problems fo GSPs and nurses interpreting the results. Reports an fredback on use of spirometers often come fro ynthusiastic practices and may not reflect accuratel the general picture ${ }^{8}$, Erevious papers hav demonstrated problems with training and support fo staff using spirometry ${ }^{0,9,1}$ Reversibility tests ar aseful in excluding asthma from COPD and $t$ establish if drug treatment is likely to be beneficial Data are lacking on the actual methods used $\mathrm{i}$ primary care to measure reversibility and th interpretation of the results.

Eractice nurses are taking an increased role in chroni respiratory care ${ }^{1}$ The aim of this survey is $t$ examine their role in the diagnosis and managemen of COPD in South West Devon and Cornwall. We als Bought to establish the problems nurses encounter i this role and the future developments they felt woul be most beneficial

\section{Method}

Subject

The practice nurse with prime responsibility fo eespiratory management was identified by telephon yalls to the receptionist or practice manager in ever practice in the South West Devon Health Authorit area, (including Plymouth and Torbay), and in th Cornwall and Isles of Scilly Health Authority Area This named individual (one per practice) was sent postal questionnaire.

The Questionnaire

The questionnaire was produced by th multidisciplinary research team in conjunction wit dour consultants in respiratory medicine and include sections on the activities of the nurse in asthma $\mathbb{C O P D}$ and spirometry. The survey was assessed an amended in two pilot studies outside the study are before it was approved for distribution

The questions included :

- If the practice owned a spirometer, who used it, how often and what training had the operator received?

- If and how reversibility testing was performed

- The nurse's knowledge and perceived usefulness of BTS guidelines 1 in the care and management of patients in primary care

- The direction of future developments of services for COPD management that would be mos important to improve the levels of care

- A general comments section

Rupert C M Jone

General Practitione

Bam Freegar

General Practitione

Mark Reeve

General Practitioner

\section{Karen Hanne}

NG

Frank Dobb

Senior Lecture

Correspondence to Dr Rupert C M Jone $\mathbb{R}$ espiratory Researc Uni

Department of Primar Health Care \& Genera Practic

玉TTC Buildin

Kamar Science Par đI Davy Roa

Derrifor

Plymout

trupertjones@ukgateway.ne

Date Submitted: $14 / 11 / 0$

Date Accepted: 20/11/0

Practices that did not respond to the questionnair jwere telephoned by the research practice nurse $(\mathrm{KH}$
Prim Care Respir

2001 10(4) $\$ 06-10$ 
and asked if 'in house' spirometry was offered. Th response rate for this question was therefore $100 \%$ \$Where other responses were unclear the nurse wa telephoned for clarification

\section{Result}

The postal response rate to the questionnaire was $64 \%$

\section{Access to Spirometr}

The survey showed that $66 \%$ of the responding nurse 由ad access to a spirometer. The non-responders wer telephoned and of these $61 \%$ had access to fpirometer, this gave an overall percentage of $64 \%$ o all practices in the South west with at least on spirometer, with a range of zero to six per practice. evide range of spirometers were employed, th majority (89\%) were able to produce a spirogram with $70 \%$ able to store and interpret electronic results.

Two practices had yet to use their spirometer and $\mathrm{i}$ A4\% spirometry was performed less than once pe week, a further $33 \%$ had used it less than 50 times i yotal. Practices without in-house spirometry usuall Peferred patients to a hospital consultant, but only 5 had direct access to hospital spirometry

\section{The Operator}

Spirometry was performed within the practice by 72 of nurses alone, by GPs alone in $9 \%$. Twenty-seve percent of the nurses had undergone formal training i the management of COPD, leading to a diploma o equivalent; the National Asthma Training Centr COPD course being most frequently attended, (80\% o those with a qualification). Formal training i gpirometry had been undertaken by $52 \%$ of respondin gurses, informal training by $41 \%$ and no training $b$ $7 \%$. Spirometers were used by staff with no forma training in $25 \%$ of practices.

BTS guideline

The BTS guidelines were very familiar to $62 \%$ of th

Elble One- The way forward: nurses' views on the importance of som proposed future developments (percentage of responders in brackets

\begin{tabular}{|c|c|c|c|c|}
\hline & Unnecessary & $\begin{array}{c}\text { Not } \\
\text { importan }\end{array}$ & Important & Essentia \\
\hline $\begin{array}{l}\text { Direct access } \\
\text { I } \boldsymbol{d} \text { spirometry in a DG }\end{array}$ & $23(22 \%$ & $B 0(29 \%$ & $\not 10 \quad 39 \%$ & $9 \quad(9 \%$ \\
\hline $\begin{array}{l}\text { Direct access to spirometr } \\
\text { in the communit }\end{array}$ & $12(11 \%$ & $18(17 \%$ & $45(43 \%$ & B1 $(29 \%$ \\
\hline $\begin{array}{l}\text { One stop clinic in th } \\
\text { district hospita }\end{array}$ & $11(10 \%$ & $19(18 \%$ & $\$ 9(56 \%$ & $17(16 \%$ \\
\hline $\begin{array}{l}\text { One stop clinic in th } \\
\text { yommunit }\end{array}$ & $2 \quad(2 \%$ & ) 11 & $56(52 \%$ & $39 \quad(36 \%$ \\
\hline $\begin{array}{l}\text { Respiratory specialist } \\
\text { support nurs }\end{array}$ & (1) $\quad(0 \%$ & $9 \quad(8 \%$ & $50 \quad(45 \%$ & $\$ 1 \quad(46 \%$ \\
\hline $\begin{array}{l}\text { tAcute assessment uni } \\
\text { \$or patients with exacerbation }\end{array}$ & ) $1 \%$ & $3 \quad(3 \%$ & $\not 3 \quad(40 \%$ & $60(56 \%$ \\
\hline $\begin{array}{l}\text { Pulmonary rehab in the } \\
\text { district hospita }\end{array}$ & $4 \quad(4 \%$ & $14(14 \%$ & $\$ 2(51 \%$ & $\$ 2(31 \%$ \\
\hline $\begin{array}{l}\text { Pulmonary rehab in the } \\
\text { yommunit }\end{array}$ & )$\quad(1 \%$ & \& $\quad(2 \%$ & $51(48 \%$ & $53(49 \%$ \\
\hline
\end{tabular}

hurses responding, quite familiar to $23 \%$ and not at al familiar to $13 \%$ of nurses. The vast majority of thos drho were familiar with the BTS guidelines foun them quite useful (61\%), $36 \%$ very useful and $3 \%$ no at all useful

Application of Spirometr

Spirometry was used for diagnosis of respirator gisease in $91 \%$, monitoring in $87 \%$ and screenin gisymptomatic smokers in $45 \%$. However, only 61 ssed reversibility testing with a wide range of method being employed

The way forward

A range of proposals for future developments t emprove services for patients was rated in importanc by the responding nurses (see table one). Of these community based options were preferred to Distric General Hospital (DGH) services. All of the option were considered to be important, particularl community based rehabilitation, $97 \%$ of nurses rated i essential or important with $96 \%$ rating an acut sssessment unit for patients with acute exacerbation as essential or important

Feedback

A total of 47 written comments were received The main groups of comments are listed: (Frequenc of specific comments in brackets)

- Fime limitations: nursing hours inadequate fo workload (4 times

- Frustration: unable to manage COPD effectively according to BTS guidelines (9 times)

- Spirometry not performed often enough to keep $\$$ kills current. (4 times

- Hack of confidence in technique and results ( times).

- Training often too limited, not relevant to primary care (twice)

- Relevant training and updates necessary for both nurses and GP's, this is dependent on time (twice) funding (twice) and area (3 times), rural practices may be at a disadvantage.

- Professional isolation (twice)

- Need more support from GP's (twice)

- Enthusiasm to provide the service in general practice (3 times)

- Used to excellent effect with smokers (4 times)

- Reduction of anxiety and travel for patients ( times)

- COPD management was not nurse led in some practices (3 times)

- The development of open access spirometry, pulmonary rehabilitation with rehabilitation in th district general hospital for oxygen dependent patients (once)

- It appears that as COPD care is initiated in practices, nurses are developing their skills, ofte financing the training and in their own time (once)

\section{Discussio}

Response to the questionnaire was $64 \%$, there is possibility of a response bias, as enthusiasti 


\section{Not to be reproduced without the permission of the Primary Care Respiratory Journa}

respiratory nurses may be more likely to respond However, telephone enquiries showed that non pesponders had a similar rate of spirometer ownershi to responders indicating little evidence of respons bias

Spirometry has been encouraged in primary care as eechnique to clarify respiratory disorders, provid appropriate diagnosis and hence decide on treatmen and prognosis ${ }^{\mathcal{P}}$ Successive surveys show that mor practices are purchasing spirometers: in 1998 Dowso eeported $21 \%$ of 84 practices in North Staffordshir ,owned a spirometer ${ }^{5}$ dnd in 1999 Rudolf reporte $62 \%$ ownership in a geographically representativ national sample ${ }^{6}$ However in practice they have bee employed with little planning.

\$pirometry in primary care is uncoordinated an disorganised. The ownership of and access $t$ spirometers in primary care practice appears extremel anbalanced with one third of practices without spirometer and others owning up to six. Those who d own one are mostly under using it, and there is no enough time or support for the nurses who are using it Đne nurse commented "COPD is a neglected area bot educationally and financially. Spirometry an enanagement of COPD has been dumped in practic nurses' laps without providing any formal training o dupport". Thus hard earned resources are being waste on expensive spirometers.

Training is critical to reliable outcomes $i$ spirometry ${ }^{9}$ gowever staff without formal trainin often perform spirometry ( $25 \%$ in this study). A COPD care is initiated in practices, some nurses ar studying for additional qualifications in their own tim and are financing the training themselves. It wa hpparent from the survey that some nurses wit appropriate training were still under confident due $\mathrm{t}$ lack of practice with new techniques and equipment Some, who have obtained training and ar enthusiastic, are unable to use their new skills becaus of practice priorities and become demoralised. On nurse said "I feel that I could be doing so much mor for my patients. Some of them have so man symptoms but seem to be on the maximum treatment I feel very frustrated".

There is little or no quality control on the accuracy o the results and real problems with interpretation. On important example is in making a diagnosis of COPD $91 \%$ of nurses stated that they used the spirometer fo sliagnosis, only $61 \%$ were doing reversibility test which are essential for separating asthma from COPD.

As nurses take on new tasks it is obvious that withou yxtra hours and adequate funding being available, the Ire unable to offer a quality service. A nurse wrote " have the skills to diagnose and manage COPD patient but my time is completely filled with other practic duties. We do not have a spirometer at the momen and I feel there would be no point getting one a work-load is already at breaking point". As ne rlirectives such as the National Service Framework fo eoronary heart diseas ${ }^{\mathfrak{B}}$ dompete for already stretche surse time, there is little room for optimism. Practice that do employ nurses for high quality COPD car enay be at a disadvantage financially when practic staff allocations are rationed.

Do address the practice nurses' problems in COP management, primary care trusts could provid eespiratory specialist nurses to work with primary car and provide 'one stop' clinics. Where there ar enthusiastic, successful practices they should b hurtured and financially supported. Such a system wil provide expert nurses, with high quality equipmen find will support and educate both primary care staf and patients. All spirometry in primary care should $b$ subjected to audit and quality control.

\section{sAcknowledgement}

diwould like to thank the many practice nurses an rloctors who contributed to this project, in particula Dr I. Coutts (Treliske Hospital), Dr C. McGavi

(Derriford Hospital), Dr J. Goldman and Dr D isinclair (Torbay Hospital) for their help in the projec design.

\section{Editors Not}

,This paper was peer reviewed for another journal hence the very short lead-time

\section{Reference}

d. British Thoracic Society. Guidelines for th management of chronic obstructive pulmonar disease: Thora 1997 : :S1-28

.2. Calverly P. Chronic obstructive pulmonary disease In the Lung Report. London: British Lung Foundatio 1996.

B.Fletcher C, Peto R. The natural history of airflo obstruction. BMJ 1977 1:1645-8

4. Britton M. Key developments in chest disease. $\mathbb{T h}$ Practitione $2001 \mathbf{8 4}: 90-5$

5. Dowson LJ, Yeung A, Allen MB. Most practice would use open access spirometry in hospitals. $\boldsymbol{B M}$ 3998: 1 ;209

6.Rudolf M. Making Spirometry Happen. Thora ;1999 54(S3 : A43

y.Pinnock H, Carley-Smith J, Kalideen D. Spirometr sn primary care: an analysis of the first 100 patient referred in one general practice. Asthma in Genera Practic 1999; 7:23-4

B.Jones RCM, Copper S. Does implementing COP guidelines improve patient care and save money $\mathrm{i}$ practice Asthma in General Practic 1999; 7:12-15. Q. Eaton T, Withy S, Garrett J et al. Spirometry i primary care practice. Ches $199961: 416-23$ 10. den Otter JJ, Knitel M, Akkermans RP et al Spirometry in general practice: the performance o practice assistants scored by lung function technicians Br J Gen Prac 1997 4 :41-2

$: 11$. Wolfe S, Price S. Delivery of asthma care patients' use of and views on healthcare services a .determined from a nationwide interview survey Asthma J 2000 O : $141-4$

A2. British Thoracic Society. Spirometry in practice: practical guide to using spirometry in primary care BTS COPD Consortium, Sept 2000.

t13. National service framework for coronary hear disease. Department of Health; March 2000 